This surfactant was prepared by the method of R.M Reed and H.V. Tartar, J. Am. Chem. Soc., 58, 322, 1936. A mixture of 0.01614 mole, $97 \%$ purity, of 1tetradecanesulfonic acid sodium salt (Aldrich Chemical Co. product) and $35 \mathrm{~mL}$ of water was stirred in a $250 \mathrm{~mL}$ beaker. A solution of 0.00807 mole of calcium chloride dihydrate in $3 \mathrm{~mL}$ of distilled water was added. The mixture was stirred, heated to $90^{\circ}$ and allowed to cool to room temperature. The solid was recovered by vacuum filtration, using ice cold water to assist in the transfer. The product was air dried and then vacuum dried in a desiccator for 2 hours. This resulted in $5.22 \mathrm{~g}$ (106\% yield) of colorless solid . product.

\section{CRITICAL MICELLE CONCENTRATION DETERMINATION}

The CMC of the above surfactants were determined by conductance and surface tension methods. Figure 1 shows the plot of observed molar conductivity versus square root of concentration. As can be seen in this figure two linear segments were obtained for each surfactant, the intersection of the segments each plot was taken to be the CMC of the respective surfactant. The observed values are $0.78 \times 10^{-5} \mathrm{M}$ and $0.82 \times 10^{-5} \mathrm{M}$ for SDDP and CaDTDS, respectively. Figure 2 shows the surface tension plot for $\mathrm{CaDTDS}$. As can be seen from this plot the intersection of the two segments of the plot which was taken to be at the CMC occurred at $0.81 \times 10^{-5} \mathrm{M}$. This is in excellent agreement with the data obtained from the conductance method.

\section{DISCUSSION OF RESULTS}

It can be seen from the results above that there is no significant difference between the observed CMC of these surfactants even though one of them, SDDP, is a 16carbon surfactant and the other CaDTDS is a 14-carbon compound. Further difference is in the fact that one contains a phosphate headgroup and the other has a sulfonate headgroup. Surfactants containing phosphate headgroups have not been extensively studied as a candidate surfactant for enhanced oil recovery. Its physical properties are therefore not thoroughly investigated and hence are not very well understood. On the other hand, sulfonate surfactants have been extensively studied for enhanced oil recovery. Its properties and capabilities are well known. However, its double-tailed analogue have not been investigated to any extent. Therefore, the research activities for this report period opens up area of great potential in view of the fact that the CMC observed in the two surfactants are extremely low with ultra low surface tension in comparison with surfactants that have been studied thus far in this project.

The salinity test, oil uptake determination and other properties of these surfactants will be presented in the next period report. 


\section{Table 1.Molar Conductivity Vs Sqrt Conc.}

$\circ$ SDDP $\quad \square \quad$ CaTDS

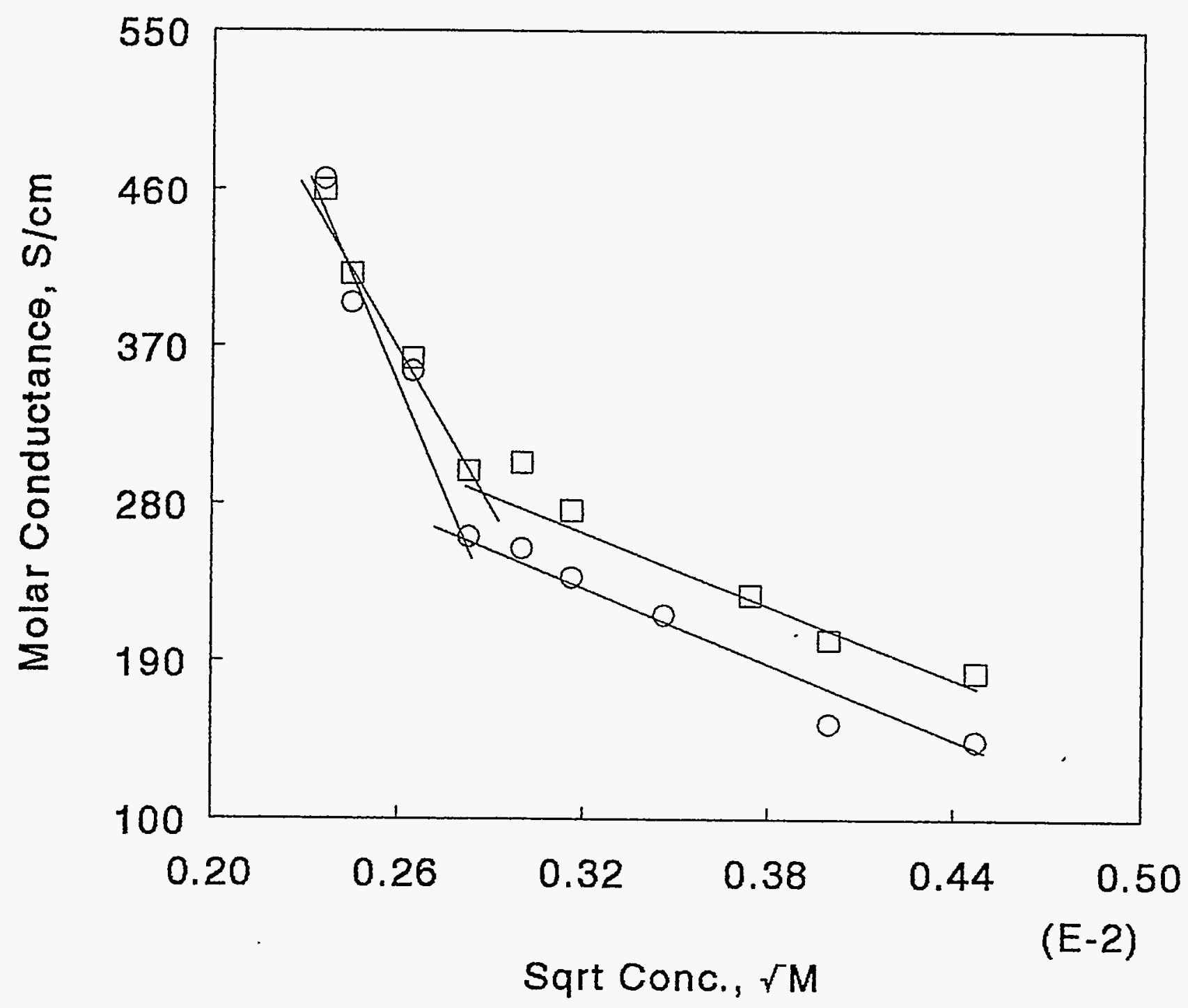


Table 2. Surface Tension Vs Sqrt Conc for SDDP

○

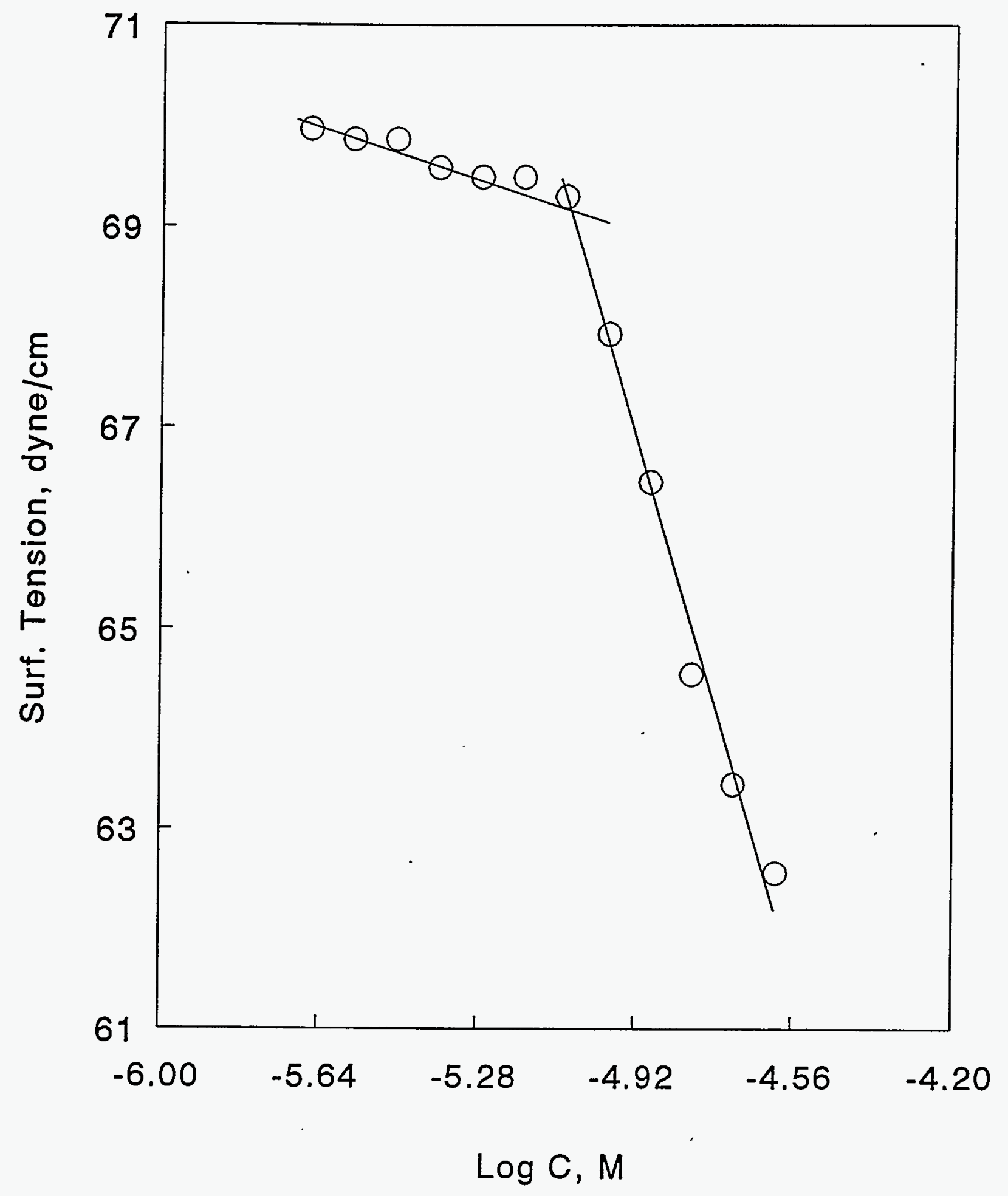


This report was prepared as an account of work sponsored by the United States Government. Neither the United States nor the United States Department of Energy, nor any of their employees, makes any warranty, express or implied, or assumes any legal liability or responsibility for the accuracy, completeness or usefulness of any information, apparatus, product or process disclosed, or represents that its use would not infringe privately owned rights. Reference herein to any specific commercial product, process, or service by trade name, mark, manufacturer, or otherwise, does not necessarily constitute or imply its endorsement, recommendation, or favoring by the United States Government or any agency thereof. The views and opinions of authors expressed herein do not necessarily state or reflect those of the United States Government or any agency thereof.

This report has been reproduced directly from the best available copy.

Available to DOE and DOE contractors from the Office of Scientific and Technical Information, P.O. Box 62, Oak Ridge, TN 37831; prices available from (615) 576-8401.

Available to the public from the National Technical Information Service, U.S. Department of Commerce, 5285 Port Royal Rd., Springfield, VA 22161. 


\section{SEVENTH QUARTERLY REPORT}

U.S. DEPARTMENT OF ENERGY

\section{SURFACTANT DEVELOPMENT FOR ENHANCED OIL RECOVERY}

GRANT NO. DE-FG22-93MT93007

Prepared By

The Morgan State University Fossil Energy Consortium

July 31, 1995

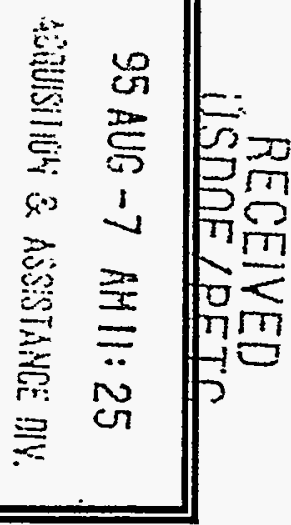




\section{SEVENTH QUARTERLY REPORT}

This quarterly report covers the period from April 1, 1995 to June 30, 1995. It summarizes activities for the ongoing research to develop novel surfactants for enhanced oil recovery, and represents the seventh quarterly report.

\section{OBJECTIVE}

The overall objective of the above project is to develop surfactant system(s) that will enhance projects on tertiary oil recovery. Such surfactant systems are expected to be stable at high temperatures and exhibit high salinity tolerance.

\section{SUMMARY OF TECHNICAL PROGRESS REPORT}

Research efforts by Morgan State University and South Carolina State University have indicated, in previous reports, that double-tailed surfactants show very good promise, as well as remarkable potential for effective tertiary oil recovery. For this reason we have continued to devote our research activities on this class of surfactants. In this report, two additional double-tailed surfactants were synthesized and their critical micelle concentration (CMC) was determined. These surfactants are sodium dihexadecyl phosphate (SDDP) and calcium ditetradecyl sulfonate (CaDTS). Both of these surfactants are anions, each with a different head group. The observed critical micelle concentration for these surfactants are $0.78 \times 10^{-5} \mathrm{M}$ and $0.81 \times 10^{-5} \mathrm{M}$, respectively. These CMC values were obtained using conductometric and surface tensiometric methods. 


\section{OVERVIEW OF SURFACTANT SYNTHESES}

Sodium Dihexadecyl Phosphate

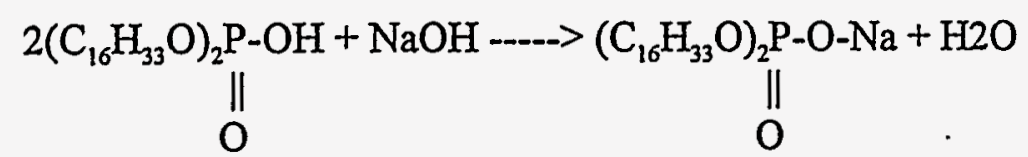

A mixture of sodium hydroxide and dihexadecyl phosphate in equimole proportion $(0.01830$ and $60.0 \mathrm{~mL}$ of water was stirred overnight in a $250-\mathrm{mL}$ Erlenmeyer flask. The mixture was transferred to a $250-\mathrm{mL}$ round-bottomed flask, and the water was removed under vacuum on a rotary evaporator. The product was a white solid weighing $10.69 \mathrm{~g}$ (103\% yield). Both reagents were obtained from Aldrich Chemical Company.

\section{Calcium Ditetradecyl Sulfonate}

$2 \mathrm{CH}_{3}\left(\mathrm{CH}_{2}\right)_{13} \mathrm{SO}_{3} \mathrm{Na}+\mathrm{CaCl}_{2} \longrightarrow \cdots\left[\mathrm{CH}_{3}\left(\mathrm{CH}_{2}\right)_{13} \mathrm{SO}_{3}\right]_{2} \mathrm{Ca}+2 \mathrm{NaCl}$

This surfactant was prepared by the method of R.M. Reed and H.V. Tartar, J.Am. Chem. Soc., 58,322,1936. A mixture of 0.01614 mole, 97\% purity, of 1 tetradecanesufonic acid sodium salt (Aldrich Chemical Co. product) and $35 \mathrm{~mL}$ of water was stirred in a $250 \mathrm{~mL}$ beaker. A solution of 0.00807 mole of calcium chloride dihydrate in $3 \mathrm{~mL}$ of distilled water was added. The mixture was stirred, heated to $90^{\circ}$ and allowed to cool to room temperature. The solid was recovery by vacuum filtration, using ice cold water to assist in the transfer. The product was air dried and then vacuum dried in a desiccator for 2 hours. This resulted in $5.22 \mathrm{~g}$ (106\% yield) of colorless solid product.

\section{CRITICAL MICELLE CONCENTRATION DETERMUNATION}

The CMC of the two previous referenced surfactants were determined by conductance and surface tension methods. Figure 1 shows the plot of observed molar conductivity versus the square root of concentration. As can be seen in this figure, two linear segments were obtained 
Figure 1

Molar Conductivity vs. Square Root of Concentration

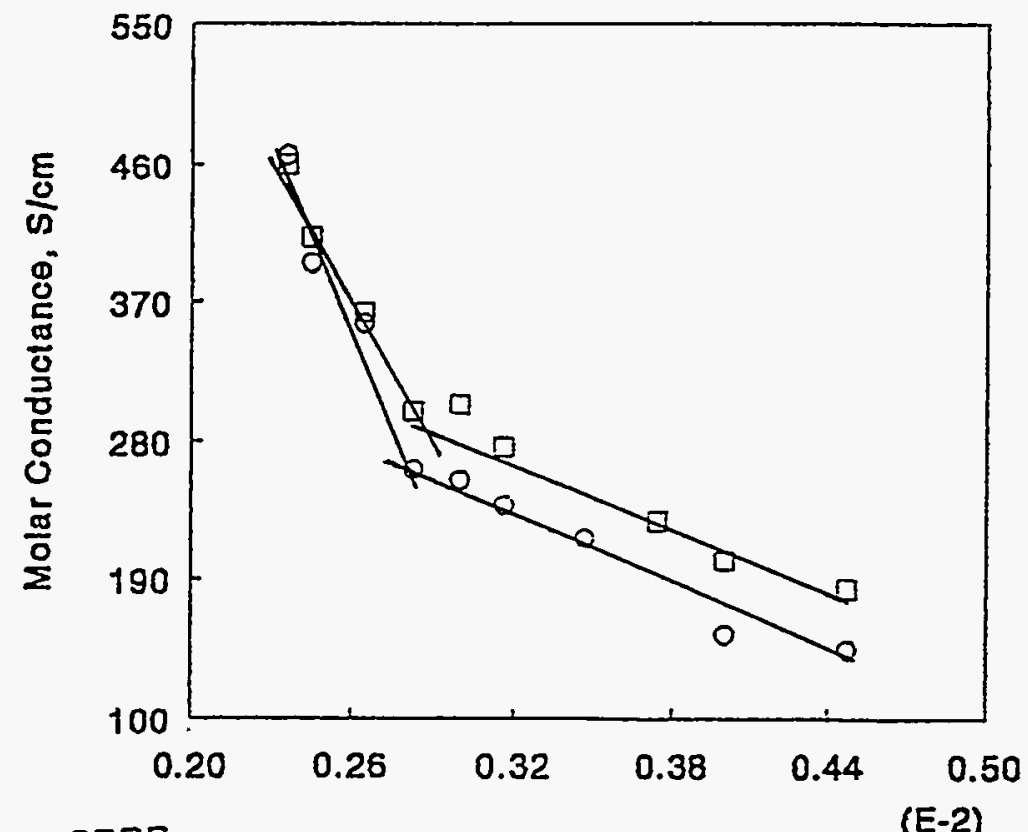

- SDDP

Sqrt Conc., $r M$

(E-2)

a CaTDS

Figure 2

Surface Tension. vs. Square Root of Concentration for SDDP

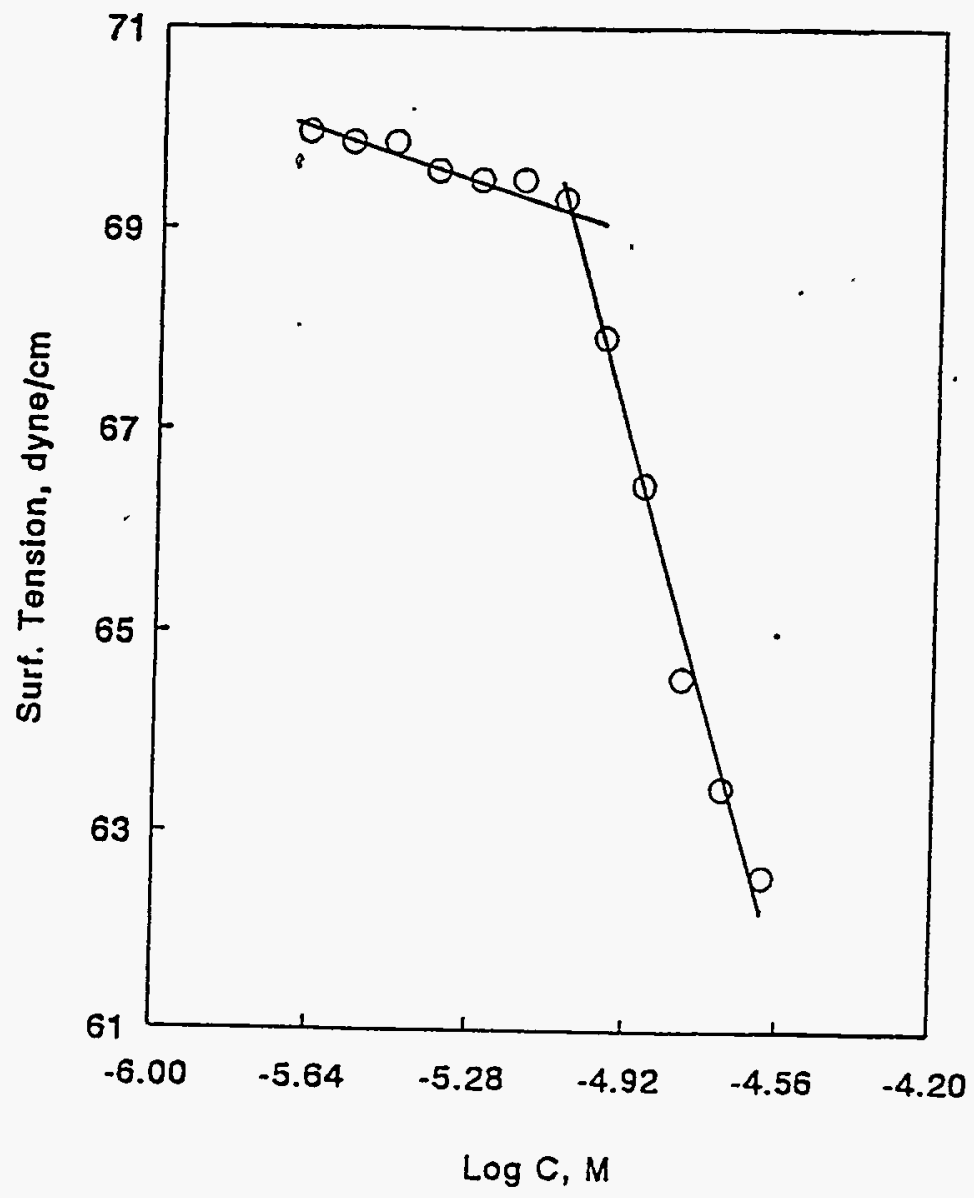


for each surfactant; the intersection of the segments for each plot was taken to be the CMC of the respective surfactant. The observed values are $0.78 \times 10^{-5} \mathrm{M}$ and $0.82 \times 10^{-5} \mathrm{M}$ for SDDP and $\mathrm{CaDTDS}$, respectively. Figure 2 shows the surface tension plot for CaDTDS. As illustrated by this plot, the intersection of the two segments of the plot which was taken to be at the CMC, occurred at $0.81 \times 10^{-5} \mathrm{M}$. This is in excellent agreement with the data obtained from the conductance method.

\section{DISCUSSION OF RESULTS}

As indicated by the previously presented results, there is no significant difference between the observed CMC of the referenced surfactants, even though one of them, SDDP, is a 16-carbon surfactant and the other, CaDTDS, is a 14-carbon compound. It should be noted, however, that one contains a phosphate headgroup, and the other has a sulfonate headgroup. Surfactants containing phosphate headgroups have not been extensively studied as a surfactant candidate for enhanced oil recovery. The physical properties of these surfactants with phosphate headgroups, therefore, have not been thoroughly investigated, and hence, are not very well understood. On the other hand, sulfonate surfactants have been extensively studied for enhanced oil recovery. Their properties and capabilities are well known. However, the double-tailed analogue of the sulfonate surfactants have not been investigated to any great extent. Consequently, the research activities for this report period opens up an area of great potential in view of the fact that the CMC observed in the two surfactants are extremely low with ultra low surface tension, in comparison with surfactants that have been studied thus far during the period project.

The salinity test, oil uptake determination, and other properties of these surfactants will be presented in the next period report. 